Comment

\title{
Comment on Hicham Bahi, et al. Effects of Urbanization and Seasonal Cycle on the Surface Urban Heat Island Patterns in the Coastal Growing Cities: A Case Study of Casablanca, Morocco. Remote Sens. 2016, 8, 829
}

\author{
Brent M. Lofgren
}

National Oceanic and Atmospheric Administration, Great Lakes Environmental Research Laboratory, Ann Arbor, MI 48108, USA; Brent.Lofgren@noaa.gov; Tel.: +1-734-741-2383

Academic Editor: Prasad S. Thenkabail

Received: 9 December 2016; Accepted: 11 January 2017; Published: 20 January 2017

\begin{abstract}
A statement in this recently published paper makes a point that is largely at odds with the main point of the paper that is cited. Stating that higher air temperatures lead to greater evapotranspiration is an oversimplification; the true story is more complex. Although this is by no means central to the conclusions of the paper being commented on, we have demonstrated the danger in taking too literally the idea that air temperature determines potential evapotranspiration.
\end{abstract}

Keywords: climate change; evapotranspiration; land-atmosphere interaction; surface energy budget

\section{Comment}

Thanks to Bahi et al. [1] for their contribution to the knowledge of the urban heat island effect and for citing our paper [2]. However, their statement that accompanies the citation, "The presence of high air temperature in winter lead to soil moisture deficit ... " is at odds with the main message of our paper. If someone were to ask, "Does higher air temperature cause higher evapotranspiration?" my answer would be that it is a factor, but is only a part of a more complex picture. As in the Priestley-Taylor formula [3], potential evapotranspiration (PET) is driven more fundamentally by net radiation flux at the surface, which in turn is strongly dependent on the time of year. Therefore, the true primary driver (net surface radiation associated with season) can be highly correlated with air temperature, with their strongest mode of variation (the annual cycle) in phase, yet air temperature and net surface radiation need to be regarded separately as drivers of evapotranspiration (ET).

Our paper [2] and its recent follow-up [4] are focused on the ill effects of applying scenarios of climate change to a land hydrologic model built on the assumption that air temperature is a good proxy that can be used alone to predict PET. The Large Basin Runoff Model (LBRM) [5] has been used multiple times as part of a process for projecting levels of the Laurentian Great Lakes on the U.S.-Canadian border. Its scheme for calculating PET differs from most other schemes whose primary input file consists of air temperature data, such as that of Hamon [6], in that the others internally generate information relating to the time of year (such as hours of daylight) that complements air temperature as part of the equation to predict PET. In contrast, LBRM uses only air temperature as a predictor, not net radiation or anything explicitly seasonal. LBRM then calibrates nine model parameters, including one that directly determines the sensitivity of PET to air temperature.

Because a temporal decomposition of the time series of ET and air temperature shows that these two quantities are highly correlated when only the mean annual cycle portion of the time series is selected, but poorly correlated when looking only at other modes of variability [2], the calibration is 
de facto based on the correlations present in the mean annual cycle. Therefore, net surface radiation, led by incoming solar radiation, can be regarded as the primary driver of both air temperature and ET. But because LBRM attributes this correlation entirely to air temperature as the driver, it ends up creating very high sensitivity of PET to air temperature. The most extreme result that we have shown is that, using one particular global general circulation model (GCM) run for the late 21st century, PET for the land portion of the drainage basin of Lake Superior is multiplied by a factor of 565 from its historical mean [4]; because of the constraints used in calibrating LBRM, we note that this is equivalent to the presence of 565 Suns in the sky.

Others have taken a critical look at long-term projections of ET derived from temperature-driven models and found that they generally exaggerate the influence of climate warming on ET $[7,8]$. However, because of the purely temperature-only formulation of PET in LBRM, we believe that it is in a special category of unrealistic sensitivity to climate warming.

\section{Conclusions}

The points made here have little impact on the study and conclusions of Bahi et al. [1], but should be heeded by the community, as we have demonstrated the danger involved in taking too literally the idea that air temperature causes ET.

Acknowledgments: This work is supported by base funding of the National Oceanic and Atmospheric Administration's Great Lakes Environmental Research Laboratory. This is GLERL Contribution Number 1848.

Conflicts of Interest: The author declares no conflict of interest.

\section{References}

1. Bahi, H.; Rhinane, H.; Bensalmia, A.; Fehrenbach, U.; Scherer, D. Effects of urbanization and seasonal cycle on the surface urban heat island patterns in the coastal growing cities: A case study of Casablanca, Morocco. Remote Sens. 2016, 8, 829. [CrossRef]

2. Lofgren, B.M.; Hunter, T.S.; Wilbarger, J. Effects of using air temperature as a proxy for potential evapotranspiration in climate change scenarios of Great Lakes basin hydrology. J. Gt. Lakes Res. 2011, 37, 744-752. [CrossRef]

3. Priestley, C.H.B.; Taylor, R.J. On the assessment of surface heat flux and evaporation using large scale parameters. Mon. Weather Rev. 1972, 100, 81-92. [CrossRef]

4. Lofgren, B.M.; Rouhana, J. Physically plausible methods for projecting Great Lakes water levels under climate change scenarios. J. Hydrometeorol. 2016, 17, 2209-2223. [CrossRef]

5. Croley, T.E., II. Great Lakes basins (USA-Canada) runoff modeling. J. Hydrol. 1983, 64, 135-158. [CrossRef]

6. Hamon, W.R. Estimating potential evapotranspiration. Trans. Am. Soc. Civ. Eng. 1961, 87, 107-120.

7. McAfee, S.A. Methodological differences in projected potential evapotranspiration. Clim. Chang. 2013, 120, 915-930. [CrossRef]

8. Milly, P.C.D.; Dunne, K.A. Potential evapotranspiration and continental drying. Nat. Clim. Chang. 2016, 6, 946-949. [CrossRef]

(C) 2017 by the author; licensee MDPI, Basel, Switzerland. This article is an open access article distributed under the terms and conditions of the Creative Commons Attribution (CC BY) license (http:// creativecommons.org/licenses/by/4.0/). 